\title{
Biography—Robert J. Gillies
}

(C) Springer Science+Business Media, LLC, part of Springer Nature 2019

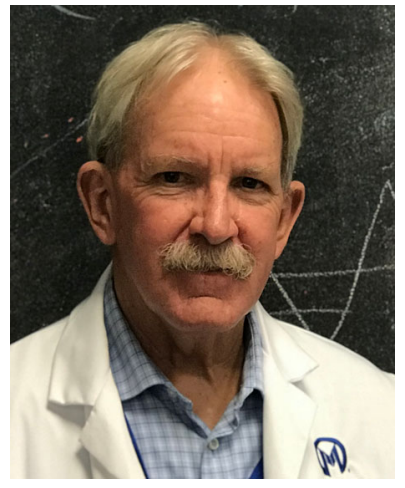

Dr. Robert J. Gillies

Dr. Robert J. Gillies is the Martin Silbiger endowed chair of the Department of Cancer Physiology and Vice-chair in the Department of Radiology for research at the H. Lee Moffitt Cancer Center and Research Institute in Tampa, Florida. He received his $\mathrm{PhD}$ in Zoology from UC Davis in 1979 under David W. Deamer and subsequently pursued a post-doctoral fellowship in in vivo Magnetic Resonance Spectroscopy at Yale University with Robert G. Shulman. He joined the faculty at Colorado State University as an Assistant Professor of Biochemistry in 1982. He moved to the University of Arizona as an associate professor with tenure in 1988 to establish a research program in biomedical Molecular Imaging. While at Arizona, he was founding directors of the Cancer Imaging program and the Advanced Research Institute for Biomedical Imaging, ARIBI. He relocated to Moffitt in 2008 as part of a major investment in radiology and imaging research.

Dr. Gillies' research is guided by the general principle that cancers are complex, dynamic, open systems fundamentally governed by the often non-linear forces of ecology and evolution. Throughout his career, Dr. Gillies has had an unwavering interest in aerobic glycolysis, a.k.a. the Warburg Effect. His major focus has been on the consequence of this altered metabolism in tumors that result in acidification of the extracellular $\mathrm{pH}$. His laboratory research program is currently investigating (1) mechanisms of adaptation to acidic microenvironments; (2) the impact of acidosis on immune surveillance; and (3) non-invasive imaging to characterize acidic and hypoxic tumor sub-regions, or "habitats."

Publisher's note Springer Nature remains neutral with regard to jurisdictional claims in published maps and institutional affiliations. 